\title{
Synergistic effect of chimeric antigen receptors and cytokine- induced killer cells: An innovative combination for cancer therapy
}

\author{
Binh Thanh Vu ${ }^{1}$, Dat Tan Le ${ }^{2}$, Phuc Van Pham ${ }^{1,3, *}$ \\ ${ }^{1}$ Laboratory of Stem Cell Research and Application, University of Science, Vietnam National University, Ho Chi Minh city, Viet Nam \\ ${ }^{2}$ Oncology Hospital, Ho Chi Minh city, Viet Nam \\ ${ }^{3}$ Faculty of Biology-Biotechnology, University of Science, Vietnam National University, Ho Chi Minh city, Viet Nam \\ *Corresponding author: pvphuc@hcmuns.edu.vn
}

Received: 03 May 2016 / Accepted: 07 June 2016 / Published online: 26 June 2016

CThe Author(s) 2016. This article is published with open access by BioMedPress (BMP)

\begin{abstract}
In recent years, the combination of gene and immunotherapy for cancer treatment has been regarded as innovative and promising; together, both therapies can help overcome limitations associated with conventional treatments. In order to augment anti-cancer efficacy and to maintain the specificity of antibody therapy, chimeric antigen receptor (CAR)-modified T cells, directed toward tumor-specific antigens, have emerged as a novel and promising therapeutic platform. CARs consist of a B cell receptor (BCR)-derived extracellular domain and $\mathrm{T}$ cell receptor (TCR)-associated signaling elements. Cytokine-induced killer (CIK) cells are the effector immune cells that can be activated ex vivo and possess both the anti-tumor potency of $\mathrm{T}$ lymphocytes and the non-major histocompatibility complex-restricted elimination of natural killer cells. With their pre-eminent ability for robust proliferation, CIK cells may overcome the main limitations of adoptive immunotherapy strategies. CIK cells have strong tumor cell killing capacity; they are effective against a wide variety of malignant tumors and have been shown to be safe in cancer patients. This review summarizes the characteristics of CARs which make them attractive for in cancer treatment strategies. In addition, the role of CIK cells and the advantages of combining CIK cells with CAR-based therapy will be discussed. Scientific evidence to support their combined therapeutic application will be highlighted, with a focus on how their innovative combination may be translated into cancer clinical trials.
\end{abstract}

Keywords: Adoptive cell therapy, chimeric antigen receptor, cytokine-induced killer cell, graft-versus-host disease, tumor-associated antigen, interleukin

\section{T CELL RECEPTOR (TCR) AND CHI- MERIC ANTIGEN RECEPTOR (CAR)}

For the immune cells, receptors play an important role in receiving signals and transferring intracellular and extracellular information; cells can interact and respond to stimuli via receptor engagement. For T cells, conventional $\mathrm{T}$ cell receptors (TCRs) have been studied for a long time. TCRs are a critical and indispensable component in the activation of $\mathrm{T}$ cells; their engagement leads to the generation of an immune response to eliminate pathogenic cells, including cancer cells (Davis et al., 2003). After interacting with major histocompatibility complex (MHC) molecule-linked antigens, TCR signaling occurs via the CD3-derived intracellular domain, which is a complex of $1 \gamma$ and $1 \delta$ chain, and $2 \varepsilon$ and $2 \zeta$ chains (Birnbaum et al., 2014). In order for the TCR interaction/engagement to be robust enough to elicit $\mathrm{T}$ cell activation, the additional engagement of the CD4 or CD8 co-receptorsis required(Kim et al., 2003). Moreover, to maintain long-term $\mathrm{T}$ cell stimulation strong enough to destroy malignant cells, $\mathrm{T}$ cells also express co-stimulatory molecules, such as CD28 or $4-1 B B$ (CD137), which play a role in promoting expression of anti-apoptotic and pro-survival factors (e.g. BCL-2, BCL-XL, and BCL2A1) (Pardoll, 2012). 
One of the significant differences between TCRs and chimeric antigen receptors (CARs) is the difference in affinity; the latter shows greater affinity maturation (increased affinity for antigen) due to its B cell receptor (BCR)-derived extracellular domain (Stone et al., 2015). However, affinity is not as important in the clinical context since expression of tumor target antigens are typically low. The weak interaction between TCR and antigen-MHC complex allows continuous TCR stimulation (serial triggering) to adequate levels of activation for $\mathrm{T}$ cells to perform their functions (Valitutti et al., 1995). Another important consideration about TCRs is how to increase the expression of CD3 molecules instead of increasing affinity. This is because CD3 has such a pivotal role in TCR-based signaling pathways (Ahmadi et al., 2011).

The application of conventional TCRs for adoptive T cell therapy has many problems still, which need to be resolved. Negative selection in the thymus makes endogenous peripheral $\mathrm{T}$ cells exhibit low affinity against self-peptide/MHC antigens. This limits the effectiveness of TCR-based therapies due to the reduction of antitumor responses. Conversely, engineered manipulation of affinity of a TCR to that of an antibody can yield cross-reactivity with self-peptides (Cameron et al., 2013). To solve the problem of crossreactivity and to enhance the therapeutic effects of adoptive $\mathrm{T}$ cell therapy using TCRs, it is necessary to identify potential target antigens as well as manipulate the affinity of individual TCRs through in silico proteome research (Schumacher and Schreiber, 2015).

The task to gather all the molecules to activate $\mathrm{T}$ cells requires each component being in good operating condition, so that they all have good spatiotemporal cooperation with each other. Another issue to keep in mind when using engineered TCRs to target cancerassociated antigens is the risk of mispairing with endogenous TCR chains, which results in the impossibility to recognize or kill cancer cells (Kuball et al., 2007). An "all in one" strategy to address the above is the use of CARs because CARs entail a combination of multiple components on a single molecule. CARs includes an extracellular domain, designed based on the antibody structure's specific association with the antigen of interest, a CD3 zeta chain-derived transmembrane domain, and an intracellular domain which attaches immunoreceptor tyrosine-rich activation motif (ITAM) molecules and co-stimulatory molecules. With the nature of antibody molecules, the interaction of a CAR and its target has much higher affinity than that of a
TCR and the same antigen. Thus, the identification of antigens on the cell surface of cancer cells by CARs is an important direction in $\mathrm{T}$ cell therapy research (Kalos et al., 2011).

The TCR-based antigen recognition is HLAdependent, i.e. the protein antigens have to be processed into peptide fragments, then presented on the cell surface by HLA molecules (Zikherman and Au-Yeung, 2015).Oneway cancer cells evade immune surveillance and targeting is through HLA downregulation. This significantly reduces the magnitude and capacity of antitumor immune responses. In contrast, CAR-based recognition is independent of HLA restriction, so this strategy not only expands the target antigen sources; besides the polypeptides, CARs can also identify the molecular composition of lipids and carbohydrates and thus, can increase the scope of application to cancer patients, independent of their HLA haplotypes (Jensen and Riddell, 2015).

\section{GENETICALLY MODIFIED T LYM- PHOCYTES WITH CHIMERIC ANTI- GEN RECEPTOR (CARS): HOPE FOR ADVANCED CANCER PATIENTS}

While traditional cancer treatments pose the risk of creating malignant cells resistant to therapies, they have to face the risk of negatively impacting the body. Thus, immunotherapy has emerged as an extremely excellent candidate cancer treatment, given its ability to activate the immune system to specifically and effectively destroy cancer cells. Immunotherapy is considered effective, but effector cells need to be activated to perform the function. The activation may come from the interaction between the HLA-antigen molecules expressed on antigen-presenting cells (APCs) and receptors expressed on cytotoxic cells (e.g., TCR on $\mathrm{T}$ lymphocytes), simultaneously with engagement between co-stimulatory molecules on APCs and CD28 on T cells. In vivo, tumors seem to essentially prevent effector cell stimulation through immunosuppressive cytokines and Tregs, in the tumor milieu, which extinguish immune responses and reverse APCs and T cells into an anergic state. While the immune system is waiting for being appropriately activated to destroy the cancer, the cancer cells may have already downregulated HLA expression, resulting in insufficient signal for cytotoxic cell activation (Seliger, 2008). To re- 
duce dependence on APCs and HLA molecules, genetically modified $\mathrm{T}$ lymphocytes with CARs can be used.

A CAR construct contains 4 regions, including an extracellular target binding domain, hinge region, transmembrane domain, and intracellular signaling domain. region has an important role in the activation of $\mathrm{T}$ cells to destroy target cells without requiring any co-stimulatory signals. The extracellular domain is comprised of a light and heavy chain of single chain variable fragment $(\mathrm{scFv})$ derived from monoclonal antibody molecules, with the aim of directly recognizing tumor-associated antigen (TAA) (Stewart-Jones et al., 2009). The hinge (or extracellular spacer) region is responsible for targeting epitopes with different distance from the cell membrane (Guest et al., 2005). The transmembrane domain anchors CAR to the cell surface, and the intracellular domain stimulates signal cascades expressing factors for $\mathrm{T}$ lymphocyte proliferation and persistence, and function against the target cell (James et al., 2008). Although most TCRs and BCRs only recognize peptide fragments that have been processed, the CAR-based recognition can identify all proteins, carbohydrates and lipids on the cell surface (Mezzanzanica et al., 1998; Pule et al., 2005; Westwood et al., 2005; Wilkie et al., 2008). Additionally, this identification is non-MHC-restricted which expands the potential application of CARs. CARbased therapy is the quintessential achievement in cellular immunology, synthetic biology and cellprocessing technology (Chinnasamy et al., 2013; Hudecek et al., 2013; Zhang et al., 2007b).

CAR studies have been extensively conducted to improve CAR-generating technology.Scientists have divided CAR into 3 different generations based on intracellular domain components. The $1^{\text {st }}$ generation CARs only mediate ITAM-based signaling, which limit T cell proliferation and persistence. However, $2^{\text {nd }}$ and $3^{\text {rd }}$ generation CARs combine one or more co-stimulatory molecules, respectively, such as CD27, CD28, CD134 (OX40), and CD137 (4-1BB). In the near future, the $4^{\text {th }}$ generation will soon appear with the design of an extracellular domain utilizing fully human antibody $(\mathrm{Ab})$, unlike the majority of CARs that contain scFv from murine or humanized $\mathrm{Ab}$ (Kochenderfer et al., 2010; Till et al., 2008).

The transfer of CAR-encoding genes into T cells is easily achieved through viral-based methods (Colovos et al., 2012). Retroviral and lentiviral vectors have been proven safe from clinical studies conducted over long periods of time (McGarrity et al., 2013). Moreover, the requirement of transient expression of a transgene with viral-based methods can be easily resolved with Ad5/F35 adenoviral vectors (Schroers et al., 2004). The concern about viral-based gene transfer methods being possibly inserted into the cell genome can be solved by the use of non-viral based approaches (PikeOverzet et al., 2007). Gene transfer by transposon/transposase system, titled Sleeping Beauty or piggyBac, allows for the persistent high-level gene expression (Huang et al., 2008; Jin et al., 2011; Nakazawa et al., 2011; Singh et al., 2008). In cases where the target antigen is also expressed on normal cells, RNA electroporation can be used to create transiently expressed CARs with almost $100 \%$ transduction efficiencies (Birkholz et al., 2009; Zhao et al., 2010). Another approach is to use retro-transposon systems which have also shown encouraging results. Genetically modified T cells with CARs, overall, represent a safe and long-term expression approach. The disadvantages of non-viral based gene transfer methods are the relatively low gene transfer efficiency, prolonged manipulation time, and creation of effector cells with exhausted and/or anergic conditions; all of these factors can significantly reduce the efficacy of immunotherapy (Manuri et al., 2010).

Once it was recognized that effector cells, particularly lymphocytes, play an important role in destroying cancer cells (Rosenberg, 2001), the first clinical studies being initiated were those involving the use of donor lymphocyte infusion (DLI) in cancer therapy. The use of lymphocytes without selecting for those with specific effects on cancer cells has led to a significant risk of Graft versus Host Disease (GvHD) induction (Takami et al., 2005). The rapid discovery of TAAs, which include tissue-specific antigens, differentiation antigens and ubiquitously expressed antigens, has paved the way for immunotherapies based on genetically engineered $\mathrm{T}$ lymphocytes (Kessler and Melief, 2007). However, these self-origin TAAs imply the low incidence of immune reaction due to the low avidity of cytotoxic effector lymphocytes and the inhibitory effect of regulatory $\mathrm{T}$ cells resulting from tolerance (Chicaybam et al., 2011).

Although a wide variety of monoclonal antibodies has been approved and translated into the clinic for cancer treatment, it is generally accepted that $\mathrm{T}$ cells possess stronger anti-tumor activity than antibodies. It is obvious that effector $\mathrm{T}$ cells, as flexible cells, can penetrate into tumor tissues, then expand and generate 
memory cells (Hillerdal and Essand, 2015). Adoptive cell therapy (ACT) involves a process of tumorreactive cell isolation (from the host), ex vivo stimulation and infusion of effector cells back into the host. However, it is still unclear that which kind of T cells should be used. Moreover, regarding to the isolation and expansion of naturally occurring TAA-specific Tcell clones, there are many obstacles related to technique, time and labor (Rosenberg et al., 2008).

Gene therapy has provided a great application in many fields of medicine, including cancer therapy, and continues to garner great interest. To augment the efficacy but keep the specificity of antibody-mediated immunity, CAR-modified $\mathrm{T}$ cells directed toward tumor-specific antigens are now emerging as a novel and promising therapy. As previously highlighted, the assembly of CAR from a BCR-derived extracellular domain and TCR-associated signaling elements (Sadelain et al., 2003) gives CAR T cells the combined advantages of both cellular and humoral immunity. This dual strategy in immunotherapy potentially allows for targeting any tumor with a high level of specificity (Biagi et al., 2011; Eshhar et al., 1993; Irving et al., 1993; Letourneur and Klausner, 1991).

Upon exposure to cognate antigen, CAR T cells secrete cytotoxic factors leading to cancer cell destruction. Cancer cells have the ability to turn down the expression of surface molecules to prevent recognition by antibodies and killing by the perforin/granzyme mechanism. By inhibiting these mechanisms, cancer cell apoptosis is affected (minimized), in addition, resistance to antibody and complement is elevated. However, activated CAR T cells are stimulated to secrete cytokines which are responsible for anti-tumor immune responses (Biagi et al., 2007; Dotti and Heslop, 2005; Kohn et al., 2011; Rossig and Brenner, 2004). Engineered $\mathrm{T}$ cells, therefore, have a superior advantage over native $\mathrm{T}$ cell in that the selection and expansion procedure take places quickly and the immune response is durable. Together, use of this type of therapy can significantly improve clinical outcome of advanced cancers (June, 2007).

Using transducer TCRs, the risk to form hybrids with endogenous TCRs can easily occur, causing false recognition and stimulating the process of destroying normal cells. In the case of modified T cells, effector cells can be designed with a multitude of signaling domains, requiring multiple simultaneous receptorligand interactions to trigger target cell killing activity. In addition, they are also designed to operate efficient- ly in the immunosuppressive tumor milieu. The value of chimeric receptors in CAR T cells is that the binding affinities of the extracellular domain, i.e. scFvs, are much more effective (Beckman et al., 2007; Richman and Kranz, 2007). In the case of target antigens also expressed on normal cells (but at a different level than cancer cells), CAR T cells can be designed with scFv having suitable yet varying affinities. In essence, they can potentially discriminate between cells with low and high antigen expression, then destroy the malignant cells (Alvarez-Vallina and Russell, 1999; Chmielewski et al., 2004; Westwood et al., 2009). Killing cancer cells can initiate the process of antigen spreading; a diversified source of cancer antigens is released and respectively activates a rich source of immune cells that can destroy several targets on the tumor cells (Hombach et al., 1999).

As mentioned above, the intracellular domain of chimeric receptors has a communicative role to the nucleus through transcription factors to activate mechanisms to destroy the target cell (Eshhar et al., 1996). CARs of the 1st generation only contain ITAM-bearing receptors, which alone induce poor cell proliferation, suboptimal cytokine secretion, and transient antitumor reaction (Brocker, 2000; Brocker and Karjalainen, 1998). Full T cell activation, however, requires at least 2 signals: the first is the interaction of the TCR/CD3 complex with MHC-peptide complex, the latter is the costimulatory signal through CD28-B7 interaction (Shirasu and Kuroki, 2012). That is the reason which prompted the generation of the 2nd and 3rd generations CARs, which feature the addition of more costimulatory domains (Van Gool et al., 1996). It has been shown that the relative position between the CD28 domain, the CD3 zeta chain and the trans-membrane domain have an impact on the activity of the modified $\mathrm{T}$ cells (Geiger et al., 2001). Many studies have also shown that the 2nd and 3rd generations have synergistic action on cell proliferation (Beecham et al., 2000; Maher et al., 2002), secretion of cytokines leading to activation of antitumor immune responses (Haynes et al., 2002b; Hombach et al., 2001a; Hombach et al., 2001b), facilitation of the persistence of effector T cells (Finney et al., 2004; Kowolik et al., 2006), and enhancement of antitumor activity (Brentjens et al., 2007; Haynes et al., 2002a; Vera et al., 2006).

To date, one of the major causes of adoptive cell therapy failure is that after infusion in the body, effector cells cannot overcome the inhibitory tumor microenvironment. In the process of formation and develop- 
ment of tumors, cancer cells have developed and perfected mechanisms of immune tolerance. They have become formidable to the immune system even to the point of immune modulation through multiple mechanisms of action, including interacting with molecules on the cell surface or through soluble factors (Rabinovich et al., 2007). The immunosuppressive effects of tumors facilitate the proliferation of Tregs and almost entirely extinguishes any immunity induced by the adoptively transferred cells as they try to penetrate the tumor (Loskog et al., 2006; Zou, 2006).

For gene therapy, one of the major benefits is the ability to design therapeutic genes for transfer into the desired cells, including $\mathrm{T}$ cells. The immunosuppressive microenvironment of the tumor is clear and irreversible, so a new approach in line with the actual situation is to turn inhibition signals into activating ones. One way is to create chimeric receptors having an inhibitory extracellular domain but an intracellular signaling domain derived from costimulatory molecules. This relatively new approach has shown encouraging results for cell surface molecules, such as CTLA-4 (Shin et al., 2012), PD-1 (Ankri and Cohen, 2014), and inhibitory cytokine receptors (Leen et al., 2014).

The $3^{\text {rd }}$ generation CARs were created by combining costimulatory molecules from the tumor necrosis factor receptor superfamily (Croft, 2009; Greenwald et al., 2005). This combination does not impede but rather augments $\mathrm{T}$ cell functions, including proliferation (Hombach and Abken, 2007), cytokine secretion, survival (Redmond et al., 2009), and antigen-specific tumor cell lysis (Melero et al., 2008; Milone et al., 2009; Stephan et al., 2007; Wang et al., 2007; Zhang et al., 2007a; Zhao et al., 2009). However, there is evidence indicating that CARs with a tripartite signaling domain can automatically trigger and producing large amounts of cytokines, which are toxic to the organ systems and ultimately limit the ability of their clinical application (Cartellieri et al., 2010).

Recombinant gene technology has enabled CAR T cell research to advance. The infusion of CAR T cells using murine-derived $\mathrm{scFv}$ into the body can activate the immune system to eliminate effector cells before they can reach the cancer cells. To overcome this obstacle, human-associated antibodies to construct novel CARs are now widely studied (Morgan et al., 2010). Modified CARs help $\mathrm{T}$ cells maintain persistence and function to destroy cancer cells. Sometimes, grafted cells mistakenly destroy normal cells based on the expression of certain molecules on the cell surface. This oc- curs since cancer cells, as cells derived from normal cells, have self-proteins and similar marker expression as normal cells. This feature allows them to progress beyond detection by the immune system. However, it poses the risk of autoimmunity, when $\mathrm{T}$ cells are targeted against proteins shared by tumors and normal cells. Thus, the possibility of autoimmunity is present and the impact is incalculable. For complete control and timely intervention in the event undesired reactions occur, transduced cells should be introduced with inducible suicide genes (Ramos and Dotti, 2011). This approach includes the thymidine kinase gene of Herpes Simplex Virus (HSV-TK) (Borchers et al., 2011), Casp9 suicide system (Ciceri et al., 2009; Di Stasi et al., 2011; Tey et al., 2007), human CD20 (Vogler et al., 2010), and mutant human thymidylate kinase (mTMPK). The above causes cell sensitivity to the corresponding prodrugs: ganciclovir (GCV), nontoxic AP1903 drug (Hoyos et al., 2010), monoclonal antibody Rituximab, or zidovudine (AZT) (Sato et al., 2007).

Many research studies have shown that combinatorial strategies with novel therapies improve traditional therapies, and are more effective at eliminating cancer. Specifically, non-myeloablative chemotherapy or radiotherapy prior to CAR-engineered $\mathrm{T}$ cell infusions have obtained many promising results (Dudley et al., 2008; Kalos et al., 2011; Rosenberg et al., 2011). At the present, the tumor microenvironment is a heterogeneous population of malignant cells and normal cells, along with the presence of a variety of cytokines (including pro-inflammatory and immunosuppressive ones). In particular, it has been documented that the tumor environment contains an abundant presence of Tregs and immunosuppressive cytokines. Nonmyeloablative chemotherapy or radiotherapy at tumor sites helps promote immunity by deletion of Tregs cells (Curiel et al., 2004) and elimination of cytokine sinks (Gattinoni et al., 2005). A more useful impact of preconditioning is the induction of tumor cell death, leading to antigen spreading, and subsequently inducing a variety of immune responses on multiple tumor targets (Russo et al., 2000).

There have been many studies on the route for $\mathrm{T}$ cell administration to determine which route enables effector cells to reach tumor sites most effectively. The routes of infusion have included intravenous injection, subcutaneous injection, intraperitoneal injection (into the abdominal cavity), intranodal injection (into lymph nodes near the tumor), and intratumoral injection. With the advancement of transgenic technology, 
T cells can be designed and modified with chemokine receptors which promote mechanisms of stem cell/T cell homing. Another approach is by binding to CAR $\mathrm{T}$ cells growth factor receptors which facilitate migration to the tumor microenvironment (Hillerdal and Essand, 2015).

Recent data show that more than 30 clinical trials using CAR $\mathrm{T}$ cells are being evaluated (www.clinicaltrials.gov). These studies show the available application of CAR-based adoptive cell transfer for the treatment of a variety of cancers (Cheadle et al., 2012). Although CAR T cells show strong potential in cancer treatment, many areas still remain to be investigated, including the selection and optimization of CAR T cell generation, the optimal tumor associated antigens (TAA), and components of CAR signaling to best promote persistence, function and survival of modified $T$ cells. In addition, the design of homing and suicide genes are also important to achieve optimal function in vivo at the tumor environment (Han et al., 2013).

\section{CYTOKINE-INDUCED KILLER (CIK) CELLS AND SYNERGISTIC EFFECT OF COMBINATION OF CARS AND CIK CELLS}

All kinds of immune cells have been tested for adoptive cell therapy, $\mathrm{T}$ lymphocytes have been widely studied; these include tumor infiltrating lymphocytes (TILs) and lymphokine-activated killer (LAK) cells. However, the applicability of the aforementioned cell types for clinical trials is not suitable due to low number cell isolation, insufficient proliferation, and high cytokine concentrations needed for cell maintenance. The tumor microenvironment contains diversified immunosuppressive cells, soluble ligands, and cytokines; these include Tregs, myeloid-derived suppressor cells (MDSCs), TAMs, interleukin (IL)-10, and transforming growth factor (TGF)-beta. All of these makes the space in the tumor microenvironment cramped, contributing to the reduction of effector-totarget ratio and thus reduction to eradicate the cancer, particularly advanced stage. For positive clinical outcome to be achieved, T lymphocytes must satisfy these requirements: have adequate number, traffic to tumor, expand in vivo, and persist long enough to induce anti-tumor responses. In the case of CAR T cells, they also need to efficiently and safely introduce the therapeutic gene(s); the engineered $\mathrm{T}$ cells must also expand to sufficient numbers.

CIK cells have generated significant attention because they are a type of $\mathrm{T}$ lymphocytes with a non-MHC restricted killing capacity of NK cells (Laport et al., 2011). CIK cells are very suitable for ACT since they are easily activated in vitro. While CIK cells are a heterogeneous cell population, $\mathrm{CD} 3{ }^{+} \mathrm{CD} 56^{+}$cells are considered primarily responsible for the function of CIK cells. CIK cell-based preclinical and clinical studies have shown antitumor responses in many blood cancers and solid tumors (Guo and Han, 2015; Jiang et al., 2013).

The addition of basic cytokine activated $\mathrm{T}$ cells with low concentrations of cytokines, including interferon (IFN)-gamma, anti-CD3 mAb and IL-2, CIK cells can be obtained easily in a short time (within 2-3 weeks from blood mononuclear cells) when cultured $e x-$ vivo(Sangiolo, 2011). Notably, only IL-2 is required to maintain the proliferation of CIK cells during the time, and can be replaced by other cytokines with similar function, such as IL-15. Effector cell number after the differentiation process dramatically increases, creating adequate quantities of immune effectors for multiple adoptive infusions, and thereby overcoming the main limitation of adoptive immunotherapy strategies using LAK cells or TILs. Similar to NK cells, CIK cells express NKG2D molecules responsible for interacting with MIC A/B or ULBP molecules on tumor cells, thus causing MHC-unrestricted tumor cell killing. This is beneficial since cancer cells are able to evade T-cell mediated killing through downregulation of their MHC expression. Another important characteristic to consider, in the context of CIK research, is that CIKs have reduced alloreactivity across HLA-barriers, which may result from their ability to secrete abundant IFN-gamma. This property adds significant value to the use of CKs in translational medicine, especially after allogeneic hematopoietic cell transplant (Sangiolo, 2011).

Studies of CIKs are continue to increase and are now included, as a standard, among clinical trial data and statistical studies related to cancer treatments. To date, there are more than 45 CIK studies in the database, covering 22 different tumor entities and with 3000 patients enrolled. CIK therapy has shown improvement of clinical responses with minor side effects. Molecularly, CIK cells can change into numerous immunologic subsets and cytokine secretion. Thus, CIKs 
represent a new type of $\mathrm{T}$ cells with great promise for cancer immunotherapy (Hontscha et al., 2011; Schmeel et al., 2015).

The unique advantages of CAR and CIK cells, and their combination, were first studied and highlighted by Marin et al. in 2006. CIK cells are akin to cytotoxic $\mathrm{T}$ lymphocytes activated ex vivo and there is a risk they may identify and destroy normal cells of the body. To avoid adverse events related to "on-target off-tumor toxicity", CIKs should be engineered to recognize their targets but cause minimal damage to normal cells. This can be solved by use of either APCs, such as dendritic cells, or CIK cells-transducedtumor antigen-encoded gene transfer. Each strategy has its own advantages and disadvantages. With the latter strategy, we do not need to isolate a differentiated cell type but rather can focus on the culture and manipulation of CIK cells. In a study using CIK cells transduced with anti-CD19 receptor for the treatment of B-ALL in vitro, the data showed that engineered CIK cells present chemotactic activity through chemokine receptor expressions, increasing their ability to migrate to B-ALL cells, and finally triggering cancer cell killing (Marin et al., 2006).

In a study evaluating a $2^{\text {nd }}$ generation CAR, the intracellular signaling domain of the CAR was modified to contain the co-stimulatory molecules 4-1BB or CD28. The results showed that effector cells increased production of a variety of immune-stimulatory cytokines, such as IL-2, tumor necrosis factor (TNF)-alpha, TNFbeta, IL-5, IL-6, and IL-8. Moreover, there was a significant reduction of IL-10 production, which significantly increased tumor cytotoxicity (Marin et al., 2007). There have been studies evaluating the efficacy of $3^{\text {rd }}$ generation CAR CIK cells at promoting destruction of acute myeloid leukemia (AML) targets. These CIK cells were genetically modified with chimeric receptors specific for the CD33 antigen. Anti-CD33 CIK cells not only affect the phenotype and function of the original cells, but also release high levels of antitumor cytokines and maintain long-term killing activity (Marin et al., 2010). However, the choice of anti-CD33 chimeric receptor is not ideal as it has been documented that CIK cells transduced with CD33 show toxicity against normal hematopoietic progenitor cells. Thus, to improve clinical applicability, different antigens should be utilized instead; a suitable antigen can be interleukin three receptor alpha (IL3RA) or CD123, which is overexpressed on the bulk AML population. Data showed that CD123-specific CARs maintain their cyto- toxicity profile towards AML targets while sparing normal hematopoietic stem/progenitor cells (HSPCs) (Tettamanti et al., 2013).

Monoclonal antibodies for cancer therapy have been used for some time, such as Herceptin for human epidermal growth factor receptor 2 (HER2)/neu positive breast cancer treatment. The establishment of CARCIK cells recognizing HER2/neu led to significant inhibition of tumor growth in a xenograft model. Effector cells are transduced easily (with more than 95\% efficiency) by RNA electroporation. In vitro, these CAR-CIK cells promoted IFN-gamma, GM-CSF and TNF-alpha production, and eliminated tumor cell lines overexpressing HER2 (Yoon et al., 2009).

To date, there is still controversy about whether $2^{\text {nd }}$ or $3^{\text {rd }}$ generation CARs will fare better in clinical trials. Hombach et al. compared CIK cells modified with CARs of $1^{\text {st }}, 2^{\text {nd }}$ and $3^{\text {rd }}$ generations. The results showed that CD28 and OX40 CARs produced the highest IFN secretion and were the most superior in redirecting tumor cell elimination. Moreover, CD28zeta-OX40 CAR accelerated CIK cell terminal maturation due to increased activation-induced cell death (AICD). Even the CD28-zeta CAR was more efficient than the CD28-zeta-OX40 CAR in increasing antigenindependent target cell lysis (Hombach et al., 2013).

\section{CONCLUSION}

With the advancement of virology, molecular biology, gene-transfer methods and $\mathrm{T}$ cell expansion, engineered $\mathrm{T}$ cell therapy has emerged as a burgeoning choice of treatment in both hematological and solid malignancies. The field of CAR T cell therapy and its application has witnessed tremendous progression within a comparatively short period of time. CAR T cell adoptive transfer has many advantages, including the particular advantage of robust in vivo cell expansion and long-term persistence. Technological improvements in CAR $\mathrm{T}$ cells manipulated with bispecific $\mathrm{Ab}$ or $\mathrm{Ab}$-drug conjugate represent promising avenues in cancer treatment.

Several questions which need to be addressed for CAR T cell technology include: (i) a careful study of antigen expression to select ideal and novel CAR $T$ cell constructs (to identify unique tumor antigens so as to avoid damage to normal tissues; (ii) evaluation of the susceptibility of particular tumor types to CAR T 
cells; (iii) development of a more competent and safer architecture of CAR, i.e. new generation CARs; and (iv) randomly conducted clinical trials to demonstrate sufficient clinical benefit.

CAR-CIK cells have gradually become a realistic new option of cancer immunotherapy. CAR-CIK has been successively studying in vitro and in vivo as a potential effective platform against a wide variety of cancers.Although many obstacles and questions still need to be resolved for CAR-CIK, it is believed, due to the strong anti-cancer activity, that CAR-CIK immunotherapy will soon become a widespread clinical strategy for cancer therapy.

\section{Abbreviations}

Ab: Antibody; Acute myeloid leukemia: AML; BCR: B cell receptor; CAR T cells: Chimeric Antigen Receptor T cells; CIK: cytokine induce killer cells; MDSCs: myeloid-derived suppressor cells; TCR: T cell receptor; TAMs: Tumor-associated macrophages; IL-10: interleukin-10; TGF: transforming growth factor; TILs: tumor infiltrating lymphocytes; TNF: tumor necrosis factor

\section{Ethics Approval and Consent to Partic- ipate}

Not applicable.

\section{Competing interests}

The authors declare they have no competing interests.

\section{Open Access}

This article is distributed under the terms of the Creative Commons Attribution License (CC-BY 4.0) which permits any use, distribution, and reproduction in any medium, provided the original author(s) and the source are credited.

\section{Acknowledgments}

This work is funded by Vietnam National University, Ho Chi Minh city, Viet Nam under grant number: TX2016-18-03.

\section{References}

Ahmadi, M., King, J.W., Xue, S.A., Voisine, C., Holler, A., Wright, G.P., Waxman, J., Morris, E., and Stauss, H.J. (2011). CD3 limits the efficacy of TCR gene therapy in vivo. Blood 118, 3528-3537.

Alvarez-Vallina, L., and Russell, S.J. (1999). Efficient discrimination between different densities of target antigen by tetracyclineregulatable T bodies. Human gene therapy 10, 559-563.

Ankri, C., and Cohen, C.J. (2014). Out of the bitter came forth sweet: Activating CD28-dependent co-stimulation via PD-1 ligands. Oncoimmunology 3, e27399.

Beckman, R.A., Weiner, L.M., and Davis, H.M. (2007). Antibody constructs in cancer therapy: protein engineering strategies to improve exposure in solid tumors. Cancer 109, 170-179.

Beecham, E.J., Ma, Q., Ripley, R., and Junghans, R.P. (2000). Coupling CD28 co-stimulation to immunoglobulin T-cell receptor molecules: the dynamics of $\mathrm{T}$-cell proliferation and death. Journal of immunotherapy 23, 631-642.

Biagi, E., Marin, V., Attianese, G.M., Pizzitola, I., Tettamanti, S., Cribioli, E., and Biondi, A. (2011). New advances in leukaemia immunotherapy by the use of Chimeric Artificial Antigen Receptors (CARs): state of the art and perspectives for the near future. Italian journal of pediatrics 37, 46 .

Biagi, E., Marin, V., Giordano Attianese, G.M., Dander, E., D'Amico, G., and Biondi, A. (2007). Chimeric T-cell receptors: new challenges for targeted immunotherapy in hematologic malignancies. Haematologica 92, 381-388.

Birkholz, K., Hombach, A., Krug, C., Reuter, S., Kershaw, M., Kampgen, E., Schuler, G., Abken, H., Schaft, N., and Dorrie, J. (2009). Transfer of mRNA encoding recombinant immunoreceptors reprograms CD4+ and CD8 $+\mathrm{T}$ cells for use in the adoptive immunotherapy of cancer. Gene therapy 16, 596-604.

Birnbaum, M.E., Berry, R., Hsiao, Y.S., Chen, Z., ShinguVazquez, M.A., Yu, X., Waghray, D., Fischer, S., McCluskey, J., Rossjohn, J., et al. (2014). Molecular architecture of the alphabeta T cell receptor-CD3 complex. Proceedings of the National Academy of Sciences of the United States of America 111, 17576-17581.

Borchers, S., Provasi, E., Silvani, A., Radrizzani, M., Benati, C., Dammann, E., Krons, A., Kontsendorn, J., Schmidtke, J., Kuehnau, W., et al. (2011). Genetically modified donor leukocyte transfusion and graft-versus-leukemia effect after allogeneic stem cell transplantation. Human gene therapy 22, 829-841.

Brentjens, R.J., Santos, E., Nikhamin, Y., Yeh, R., Matsushita, M., La Perle, K., Quintas-Cardama, A., Larson, S.M., and Sadelain, M. (2007). Genetically targeted T cells eradicate systemic acute lymphoblastic leukemia xenografts. Clinical cancer research : an official journal of the American Association for Cancer Research 13, 5426-5435.

Brocker, T. (2000). Chimeric Fv-zeta or Fv-epsilon receptors are not sufficient to induce activation or cytokine production in peripheral T cells. Blood 96, 1999-2001.

Brocker, T., and Karjalainen, K. (1998). Adoptive tumor immunity mediated by lymphocytes bearing modified antigen-specific receptors. Advances in immunology 68, 257-269.

Cameron, B.J., Gerry, A.B., Dukes, J., Harper, J.V., Kannan, V., Bianchi, F.C., Grand, F., Brewer, J.E., Gupta, M., Plesa, G., et 
al. (2013). Identification of a Titin-derived HLA-A1-presented peptide as a cross-reactive target for engineered MAGE A3directed T cells. Science translational medicine 5, 197ra103.

Cartellieri, M., Bachmann, M., Feldmann, A., Bippes, C., Stamova, S., Wehner, R., Temme, A., and Schmitz, M. (2010). Chimeric antigen receptor-engineered $\mathrm{T}$ cells for immunotherapy of cancer. Journal of biomedicine \& biotechnology 2010, 956304.

Cheadle, E.J., Sheard, V., Hombach, A.A., Chmielewski, M., Riet, T., Berrevoets, C., Schooten, E., Lamers, C., Abken, H., Debets, R., et al. (2012). Chimeric antigen receptors for T-cell based therapy. Methods in molecular biology 907, 645-666.

Chicaybam, L., Sodre, A.L., and Bonamino, M. (2011). Chimeric antigen receptors in cancer immuno-gene therapy: current status and future directions. International reviews of immunology 30, 294311.

Chinnasamy, D., Tran, E., Yu, Z., Morgan, R.A., Restifo, N.P., and Rosenberg, S.A. (2013). Simultaneous targeting of tumor antigens and the tumor vasculature using $\mathrm{T}$ lymphocyte transfer synergize to induce regression of established tumors in mice. Cancer research 73, 3371-3380.

Chmielewski, M., Hombach, A., Heuser, C., Adams, G.P., and Abken, H. (2004). T cell activation by antibody-like immunoreceptors: increase in affinity of the single-chain fragment domain above threshold does not increase $\mathrm{T}$ cell activation against antigenpositive target cells but decreases selectivity. Journal of immunology 173, 7647-7653.

Ciceri, F., Bonini, C., Stanghellini, M.T., Bondanza, A., Traversari, C., Salomoni, M., Turchetto, L., Colombi, S., Bernardi, M., Peccatori, J., et al. (2009). Infusion of suicide-gene-engineered donor lymphocytes after family haploidentical haemopoietic stemcell transplantation for leukaemia (the TK007 trial): a nonrandomised phase I-II study. The Lancet Oncology 10, 489-500.

Colovos, C., Villena-Vargas, J., and Adusumilli, P.S. (2012). Safety and stability of retrovirally transduced chimeric antigen receptor T cells. Immunotherapy 4, 899-902.

Croft, M. (2009). The role of TNF superfamily members in T-cell function and diseases. Nature reviews Immunology 9, 271-285.

Curiel, T.J., Coukos, G., Zou, L., Alvarez, X., Cheng, P., Mottram, P., Evdemon-Hogan, M., Conejo-Garcia, J.R., Zhang, L., Burow, M., et al. (2004). Specific recruitment of regulatory $\mathrm{T}$ cells in ovarian carcinoma fosters immune privilege and predicts reduced survival. Nature medicine 10, 942-949.

Davis, M.M., Krogsgaard, M., Huppa, J.B., Sumen, C., Purbhoo, M.A., Irvine, D.J., Wu, L.C., and Ehrlich, L. (2003). Dynamics of cell surface molecules during $\mathrm{T}$ cell recognition. Annual review of biochemistry 72, 717-742.

Di Stasi, A., Tey, S.K., Dotti, G., Fujita, Y., Kennedy-Nasser, A., Martinez, C., Straathof, K., Liu, E., Durett, A.G., Grilley, B., et al. (2011). Inducible apoptosis as a safety switch for adoptive cell therapy. The New England journal of medicine 365, 1673-1683.

Dotti, G., and Heslop, H.E. (2005). Current status of genetic modification of $\mathrm{T}$ cells for cancer treatment. Cytotherapy 7, 262272.

Dudley, M.E., Yang, J.C., Sherry, R., Hughes, M.S., Royal, R., Kammula, U., Robbins, P.F., Huang, J., Citrin, D.E., Leitman, S.F., et al. (2008). Adoptive cell therapy for patients with metastatic melanoma: evaluation of intensive myeloablative chemoradia- tion preparative regimens. Journal of clinical oncology : official journal of the American Society of Clinical Oncology 26, 5233-5239.

Eshhar, Z., Bach, N., Fitzer-Attas, C.J., Gross, G., Lustgarten, J., Waks, T., and Schindler, D.G. (1996). The T-body approach: potential for cancer immunotherapy. Springer seminars in immunopathology 18, 199-209.

Eshhar, Z., Waks, T., Gross, G., and Schindler, D.G. (1993). Specific activation and targeting of cytotoxic lymphocytes through chimeric single chains consisting of antibody-binding domains and the gamma or zeta subunits of the immunoglobulin and T-cell receptors. Proceedings of the National Academy of Sciences of the United States of America 90, 720-724.

Finney, H.M., Akbar, A.N., and Lawson, A.D. (2004). Activation of resting human primary $\mathrm{T}$ cells with chimeric receptors: costimulation from CD28, inducible costimulator, CD134, and CD137 in series with signals from the TCR zeta chain. Journal of immunology 172, 104-113.

Gattinoni, L., Finkelstein, S.E., Klebanoff, C.A., Antony, P.A., Palmer, D.C., Spiess, P.J., Hwang, L.N., Yu, Z., Wrzesinski, C., Heimann, D.M., et al. (2005). Removal of homeostatic cytokine sinks by lymphodepletion enhances the efficacy of adoptively transferred tumor-specific CD8 $+\mathrm{T}$ cells. The Journal of experimental medicine 202, 907-912.

Geiger, T.L., Nguyen, P., Leitenberg, D., and Flavell, R.A. (2001). Integrated src kinase and costimulatory activity enhances signal transduction through single-chain chimeric receptors in $\mathrm{T}$ lymphocytes. Blood 98, 2364-2371.

Greenwald, R.J., Freeman, G.J., and Sharpe, A.H. (2005). The B7 family revisited. Annual review of immunology 23, 515-548.

Guest, R.D., Hawkins, R.E., Kirillova, N., Cheadle, E.J., Arnold, J., O'Neill, A., Irlam, J., Chester, K.A., Kemshead, J.T., Shaw, D.M., et al. (2005). The role of extracellular spacer regions in the optimal design of chimeric immune receptors: evaluation of four different scFvs and antigens. Journal of immunotherapy 28, $203-$ 211.

Guo, Y., and Han, W. (2015). Cytokine-induced killer (CIK) cells: from basic research to clinical translation. Chinese journal of cancer 34, 6.

Han, E.Q., Li, X.L., Wang, C.R., Li, T.F., and Han, S.Y. (2013). Chimeric antigen receptor-engineered T cells for cancer immunotherapy: progress and challenges. Journal of hematology \& oncology $6,47$.

Haynes, N.M., Trapani, J.A., Teng, M.W., Jackson, J.T., Cerruti, L., Jane, S.M., Kershaw, M.H., Smyth, M.J., and Darcy, P.K. (2002a). Rejection of syngeneic colon carcinoma by CTLs expressing single-chain antibody receptors codelivering CD28 costimulation. Journal of immunology 169, 5780-5786.

Haynes, N.M., Trapani, J.A., Teng, M.W., Jackson, J.T., Cerruti, L., Jane, S.M., Kershaw, M.H., Smyth, M.J., and Darcy, P.K. (2002b). Single-chain antigen recognition receptors that costimulate potent rejection of established experimental tumors. Blood 100, 3155-3163.

Hillerdal, V., and Essand, M. (2015). Chimeric antigen receptorengineered T cells for the treatment of metastatic prostate cancer. BioDrugs : clinical immunotherapeutics, biopharmaceuticals and gene therapy 29, 75-89. 
Hombach, A., and Abken, H. (2007). Costimulation tunes tumorspecific activation of redirected $\mathrm{T}$ cells in adoptive immunotherapy. Cancer immunology, immunotherapy: CII 56, 731-737.

Hombach, A., Koch, D., Sircar, R., Heuser, C., Diehl, V., Kruis, W., Pohl, C., and Abken, H. (1999). A chimeric receptor that selectively targets membrane-bound carcinoembryonic antigen (mCEA) in the presence of soluble CEA. Gene therapy 6, 300-304.

Hombach, A., Sent, D., Schneider, C., Heuser, C., Koch, D., Pohl, C., Seliger, B., and Abken, H. (2001a). T-cell activation by recombinant receptors: $\mathrm{CD} 28$ costimulation is required for interleukin 2 secretion and receptor-mediated T-cell proliferation but does not affect receptor-mediated target cell lysis. Cancer research 61, 1976-1982.

Hombach, A., Wieczarkowiecz, A., Marquardt, T., Heuser, C., Usai, L., Pohl, C., Seliger, B., and Abken, H. (2001b). Tumorspecific $\mathrm{T}$ cell activation by recombinant immunoreceptors: CD3 zeta signaling and CD28 costimulation are simultaneously required for efficient IL-2 secretion and can be integrated into one combined CD28/CD3 zeta signaling receptor molecule. Journal of immunology 167, 6123-6131.

Hombach, A.A., Rappl, G., and Abken, H. (2013). Arming cytokine-induced killer cells with chimeric antigen receptors: CD28 outperforms combined CD28-OX40 "super-stimulation". Molecular therapy : the journal of the American Society of Gene Therapy 21, 2268-2277.

Hontscha, C., Borck, Y., Zhou, H., Messmer, D., and SchmidtWolf, I.G. (2011). Clinical trials on CIK cells: first report of the international registry on CIK cells (IRCC). Journal of cancer research and clinical oncology 137, 305-310.

Hoyos, V., Savoldo, B., Quintarelli, C., Mahendravada, A., Zhang, M., Vera, J., Heslop, H.E., Rooney, C.M., Brenner, M.K., and Dotti, G. (2010). Engineering CD19-specific T lymphocytes with interleukin-15 and a suicide gene to enhance their anti-lymphoma/leukemia effects and safety. Leukemia 24, 11601170

Huang, X., Guo, H., Kang, J., Choi, S., Zhou, T.C., Tammana, S., Lees, C.J., Li, Z.Z., Milone, M., Levine, B.L., et al. (2008). Sleeping Beauty transposon-mediated engineering of human primary T cells for therapy of CD19+ lymphoid malignancies. Molecular therapy : the journal of the American Society of Gene Therapy 16, 580-589.

Hudecek, M., Lupo-Stanghellini, M.T., Kosasih, P.L., Sommermeyer, D., Jensen, M.C., Rader, C., and Riddell, S.R. (2013). Receptor affinity and extracellular domain modifications affect tumor recognition by ROR1-specific chimeric antigen receptor $\mathrm{T}$ cells. Clinical cancer research : an official journal of the American Association for Cancer Research 19, 3153-3164.

Irving, B.A., Chan, A.C., and Weiss, A. (1993). Functional characterization of a signal transducing motif present in the $\mathrm{T}$ cell antigen receptor zeta chain. The Journal of experimental medicine 177 , 1093-1103.

James, S.E., Greenberg, P.D., Jensen, M.C., Lin, Y., Wang, J., Till, B.G., Raubitschek, A.A., Forman, S.J., and Press, O.W. (2008). Antigen sensitivity of CD22-specific chimeric TCR is modulated by target epitope distance from the cell membrane. Journal of immunology 180, 7028-7038.
Jensen, M.C., and Riddell, S.R. (2015). Designing chimeric antigen receptors to effectively and safely target tumors. Current opinion in immunology 33, 9-15.

Jiang, J., Wu, C., and Lu, B. (2013). Cytokine-induced killer cells promote antitumor immunity. Journal of translational medicine 11, 83.

Jin, Z., Maiti, S., Huls, H., Singh, H., Olivares, S., Mates, L., Izsvak, Z., Ivics, Z., Lee, D.A., Champlin, R.E., et al. (2011). The hyperactive Sleeping Beauty transposase SB100X improves the genetic modification of $\mathrm{T}$ cells to express a chimeric antigen receptor. Gene therapy 18, 849-856.

June, C.H. (2007). Adoptive T cell therapy for cancer in the clinic. The Journal of clinical investigation 117, 1466-1476.

Kalos, M., Levine, B.L., Porter, D.L., Katz, S., Grupp, S.A., Bagg, A., and June, C.H. (2011). T cells with chimeric antigen receptors have potent antitumor effects and can establish memory in patients with advanced leukemia. Science translational medicine 3, 95ra73.

Kessler, J.H., and Melief, C.J. (2007). Identification of T-cell epitopes for cancer immunotherapy. Leukemia 21, 1859-1874.

Kim, P.W., Sun, Z.Y., Blacklow, S.C., Wagner, G., and Eck, M.J. (2003). A zinc clasp structure tethers Lck to T cell coreceptors CD4 and CD8. Science 301, 1725-1728.

Kochenderfer, J.N., Wilson, W.H., Janik, J.E., Dudley, M.E., Stetler-Stevenson, M., Feldman, S.A., Maric, I., Raffeld, M., Nathan, D.A., Lanier, B.J., et al. (2010). Eradication of B-lineage cells and regression of lymphoma in a patient treated with autologous $\mathrm{T}$ cells genetically engineered to recognize CD19. Blood 116, 4099-4102.

Kohn, D.B., Dotti, G., Brentjens, R., Savoldo, B., Jensen, M., Cooper, L.J., June, C.H., Rosenberg, S., Sadelain, M., and Heslop, H.E. (2011). CARs on track in the clinic. Molecular therapy : the journal of the American Society of Gene Therapy 19, 432-438.

Kowolik, C.M., Topp, M.S., Gonzalez, S., Pfeiffer, T., Olivares, S., Gonzalez, N., Smith, D.D., Forman, S.J., Jensen, M.C., and Cooper, L.J. (2006). CD28 costimulation provided through a CD19-specific chimeric antigen receptor enhances in vivo persistence and antitumor efficacy of adoptively transferred $\mathrm{T}$ cells. Cancer research 66, 10995-11004.

Kuball, J., Dossett, M.L., Wolfl, M., Ho, W.Y., Voss, R.H., Fowler, C., and Greenberg, P.D. (2007). Facilitating matched pairing and expression of TCR chains introduced into human T cells. Blood 109, 2331-2338.

Laport, G.G., Sheehan, K., Baker, J., Armstrong, R., Wong, R.M., Lowsky, R., Johnston, L.J., Shizuru, J.A., Miklos, D., Arai, S., et al. (2011). Adoptive immunotherapy with cytokineinduced killer cells for patients with relapsed hematologic malignancies after allogeneic hematopoietic cell transplantation. Biology of blood and marrow transplantation : journal of the American Society for Blood and Marrow Transplantation 17, 1679-1687.

Leen, A.M., Sukumaran, S., Watanabe, N., Mohammed, S., Keirnan, J., Yanagisawa, R., Anurathapan, U., Rendon, D., Heslop, H.E., Rooney, C.M., et al. (2014). Reversal of tumor immune inhibition using a chimeric cytokine receptor. Molecular therapy : the journal of the American Society of Gene Therapy 22, 1211 1220 . 
Letourneur, F., and Klausner, R.D. (1991). T-cell and basophil activation through the cytoplasmic tail of T-cell-receptor zeta family proteins. Proceedings of the National Academy of Sciences of the United States of America 88, 8905-8909.

Loskog, A., Giandomenico, V., Rossig, C., Pule, M., Dotti, G., and Brenner, M.K. (2006). Addition of the CD28 signaling domain to chimeric $\mathrm{T}$-cell receptors enhances chimeric $\mathrm{T}$-cell resistance to T regulatory cells. Leukemia 20, 1819-1828.

Maher, J., Brentjens, R.J., Gunset, G., Riviere, I., and Sadelain, M. (2002). Human T-lymphocyte cytotoxicity and proliferation directed by a single chimeric TCRzeta /CD28 receptor. Nature biotechnology 20, 70-75.

Manuri, P.V., Wilson, M.H., Maiti, S.N., Mi, T., Singh, H., Olivares, S., Dawson, M.J., Huls, H., Lee, D.A., Rao, P.H., et al. (2010). piggyBac transposon/transposase system to generate CD19-specific T cells for the treatment of B-lineage malignancies. Human gene therapy 21, 427-437.

Marin, V., Dander, E., Biagi, E., Introna, M., Fazio, G., Biondi, A., and D'Amico, G. (2006). Characterization of in vitro migratory properties of anti-CD19 chimeric receptor-redirected CIK cells for their potential use in B-ALL immunotherapy. Experimental hematology 34, 1219-1229.

Marin, V., Kakuda, H., Dander, E., Imai, C., Campana, D., Biondi, A., and D'Amico, G. (2007). Enhancement of the antileukemic activity of cytokine induced killer cells with an antiCD19 chimeric receptor delivering a 4-1BB-zeta activating signal. Experimental hematology 35, 1388-1397.

Marin, V., Pizzitola, I., Agostoni, V., Attianese, G.M., Finney, H., Lawson, A., Pule, M., Rousseau, R., Biondi, A., and Biagi, E. (2010). Cytokine-induced killer cells for cell therapy of acute myeloid leukemia: improvement of their immune activity by expression of CD33-specific chimeric receptors. Haematologica 95, 2144-2152.

McGarrity, G.J., Hoyah, G., Winemiller, A., Andre, K., Stein, D., Blick, G., Greenberg, R.N., Kinder, C., Zolopa, A., BinderScholl, G., et al. (2013). Patient monitoring and follow-up in lentiviral clinical trials. The journal of gene medicine 15, 78-82.

Melero, I., Murillo, O., Dubrot, J., Hervas-Stubbs, S., and PerezGracia, J.L. (2008). Multi-layered action mechanisms of CD137 (4-1BB)-targeted immunotherapies. Trends in pharmacological sciences 29, 383-390.

Mezzanzanica, D., Canevari, S., Mazzoni, A., Figini, M., Colnaghi, M.I., Waks, T., Schindler, D.G., and Eshhar, Z. (1998). Transfer of chimeric receptor gene made of variable regions of tumor-specific antibody confers anticarbohydrate specificity on $\mathrm{T}$ cells. Cancer gene therapy 5, 401-407.

Milone, M.C., Fish, J.D., Carpenito, C., Carroll, R.G., Binder, G.K., Teachey, D., Samanta, M., Lakhal, M., Gloss, B., DanetDesnoyers, G., et al. (2009). Chimeric receptors containing CD137 signal transduction domains mediate enhanced survival of $\mathrm{T}$ cells and increased antileukemic efficacy in vivo. Molecular therapy : the journal of the American Society of Gene Therapy 17, 14531464.

Morgan, R.A., Yang, J.C., Kitano, M., Dudley, M.E., Laurencot, C.M., and Rosenberg, S.A. (2010). Case report of a serious adverse event following the administration of $\mathrm{T}$ cells transduced with a chimeric antigen receptor recognizing ERBB2. Molecular therapy : the journal of the American Society of Gene Therapy 18, 843-851.

Nakazawa, Y., Huye, L.E., Salsman, V.S., Leen, A.M., Ahmed, N., Rollins, L., Dotti, G., Gottschalk, S.M., Wilson, M.H., and Rooney, C.M. (2011). PiggyBac-mediated cancer immunotherapy using EBV-specific cytotoxic T-cells expressing HER2-specific chimeric antigen receptor. Molecular therapy : the journal of the American Society of Gene Therapy 19, 2133-2143.

Pardoll, D.M. (2012). The blockade of immune checkpoints in cancer immunotherapy. Nature reviews Cancer 12, 252-264.

Pike-Overzet, K., van der Burg, M., Wagemaker, G., van Dongen, J.J., and Staal, F.J. (2007). New insights and unresolved issues regarding insertional mutagenesis in X-linked SCID gene therapy. Molecular therapy : the journal of the American Society of Gene Therapy 15, 1910-1916.

Pule, M.A., Straathof, K.C., Dotti, G., Heslop, H.E., Rooney, C.M., and Brenner, M.K. (2005). A chimeric T cell antigen receptor that augments cytokine release and supports clonal expansion of primary human T cells. Molecular therapy : the journal of the American Society of Gene Therapy 12, 933-941.

Rabinovich, G.A., Gabrilovich, D., and Sotomayor, E.M. (2007). Immunosuppressive strategies that are mediated by tumor cells. Annual review of immunology 25, 267-296.

Ramos, C.A., and Dotti, G. (2011). Chimeric antigen receptor (CAR)-engineered lymphocytes for cancer therapy. Expert opinion on biological therapy 11, 855-873.

Redmond, W.L., Ruby, C.E., and Weinberg, A.D. (2009). The role of OX40-mediated co-stimulation in T-cell activation and survival. Critical reviews in immunology 29, 187-201.

Richman, S.A., and Kranz, D.M. (2007). Display, engineering, and applications of antigen-specific T cell receptors. Biomolecular engineering 24, 361-373.

Rosenberg, S.A. (2001). Progress in human tumour immunology and immunotherapy. Nature 411, 380-384.

Rosenberg, S.A., Restifo, N.P., Yang, J.C., Morgan, R.A., and Dudley, M.E. (2008). Adoptive cell transfer: a clinical path to effective cancer immunotherapy. Nature reviews Cancer 8, 299-308.

Rosenberg, S.A., Yang, J.C., Sherry, R.M., Kammula, U.S., Hughes, M.S., Phan, G.Q., Citrin, D.E., Restifo, N.P., Robbins, P.F., Wunderlich, J.R., et al. (2011). Durable complete responses in heavily pretreated patients with metastatic melanoma using $\mathrm{T}$ cell transfer immunotherapy. Clinical cancer research : an official journal of the American Association for Cancer Research 17, 4550-4557.

Rossig, C., and Brenner, M.K. (2004). Genetic modification of T lymphocytes for adoptive immunotherapy. Molecular therapy : the journal of the American Society of Gene Therapy 10, 5-18.

Russo, V., Tanzarella, S., Dalerba, P., Rigatti, D., Rovere, P., Villa, A., Bordignon, C., and Traversari, C. (2000). Dendritic cells acquire the MAGE-3 human tumor antigen from apoptotic cells and induce a class I-restricted T cell response. Proceedings of the National Academy of Sciences of the United States of America 97, 2185-2190.

Sadelain, M., Riviere, I., and Brentjens, R. (2003). Targeting tumours with genetically enhanced T lymphocytes. Nature reviews Cancer 3, 35-45. 
Sangiolo, D. (2011). Cytokine induced killer cells as promising immunotherapy for solid tumors. Journal of Cancer 2, 363-368.

Sato, T., Neschadim, A., Konrad, M., Fowler, D.H., Lavie, A., and Medin, J.A. (2007). Engineered human tmpk/AZT as a novel enzyme/prodrug axis for suicide gene therapy. Molecular therapy : the journal of the American Society of Gene Therapy 15, 962-970.

Schmeel, L.C., Schmeel, F.C., Coch, C., and Schmidt-Wolf, I.G. (2015). Cytokine-induced killer (CIK) cells in cancer immunotherapy: report of the international registry on CIK cells (IRCC). Journal of cancer research and clinical oncology 141, 839-849.

Schroers, R., Hildebrandt, Y., Hasenkamp, J., Glass, B., Lieber, A., Wulf, G., and Piesche, M. (2004). Gene transfer into human $\mathrm{T}$ lymphocytes and natural killer cells by Ad5/F35 chimeric adenoviral vectors. Experimental hematology 32, 536-546.

Schumacher, T.N., and Schreiber, R.D. (2015). Neoantigens in cancer immunotherapy. Science 348, 69-74.

Seliger, B. (2008). Different regulation of MHC class I antigen processing components in human tumors. Journal of immunotoxicology 5, 361-367.

Shin, J.H., Park, H.B., Oh, Y.M., Lim, D.P., Lee, J.E., Seo, H.H., Lee, S.J., Eom, H.S., Kim, I.H., Lee, S.H., et al. (2012). Positive conversion of negative signaling of CTLA4 potentiates antitumor efficacy of adoptive T-cell therapy in murine tumor models. Blood 119, 5678-5687.

Shirasu, N., and Kuroki, M. (2012). Functional design of chimeric $\mathrm{T}$-cell antigen receptors for adoptive immunotherapy of cancer: architecture and outcomes. Anticancer research 32, 2377-2383.

Singh, H., Manuri, P.R., Olivares, S., Dara, N., Dawson, M.J., Huls, H., Hackett, P.B., Kohn, D.B., Shpall, E.J., Champlin, R.E., et al. (2008). Redirecting specificity of T-cell populations for CD19 using the Sleeping Beauty system. Cancer research 68, 29612971.

Stephan, M.T., Ponomarev, V., Brentjens, R.J., Chang, A.H., Dobrenkov, K.V., Heller, G., and Sadelain, M. (2007). T cellencoded CD80 and 4-1BBL induce auto- and transcostimulation, resulting in potent tumor rejection. Nature medicine 13, 14401449 .

Stewart-Jones, G., Wadle, A., Hombach, A., Shenderov, E., Held, G., Fischer, E., Kleber, S., Nuber, N., Stenner-Liewen, F., Bauer, S., et al. (2009). Rational development of high-affinity Tcell receptor-like antibodies. Proceedings of the National Academy of Sciences of the United States of America 106, 5784-5788.

Stone, J.D., Harris, D.T., and Kranz, D.M. (2015). TCR affinity for $\mathrm{p} / \mathrm{MHC}$ formed by tumor antigens that are self-proteins: impact on efficacy and toxicity. Current opinion in immunology 33, 1622.

Takami, A., Okumura, H., Yamazaki, H., Kami, M., Kim, S.W., Asakura, H., Endo, T., Nishio, M., Minauchi, K., Kumano, K., et al. (2005). Prospective trial of high-dose chemotherapy followed by infusions of peripheral blood stem cells and dose-escalated donor lymphocytes for relapsed leukemia after allogeneic stem cell transplantation. International journal of hematology 82, 449-455.

Tettamanti, S., Marin, V., Pizzitola, I., Magnani, C.F., Giordano Attianese, G.M., Cribioli, E., Maltese, F., Galimberti, S., Lopez, A.F., Biondi, A., et al. (2013). Targeting of acute myeloid leukaemia by cytokine-induced killer cells redirected with a novel
CD123-specific chimeric antigen receptor. British journal of haematology 161, 389-401.

Tey, S.K., Dotti, G., Rooney, C.M., Heslop, H.E., and Brenner, M.K. (2007). Inducible caspase 9 suicide gene to improve the safety of allodepleted $\mathrm{T}$ cells after haploidentical stem cell transplantation. Biology of blood and marrow transplantation : journal of the American Society for Blood and Marrow Transplantation 13, 913-924.

Till, B.G., Jensen, M.C., Wang, J., Chen, E.Y., Wood, B.L., Greisman, H.A., Qian, X., James, S.E., Raubitschek, A., Forman, S.J., et al. (2008). Adoptive immunotherapy for indolent nonHodgkin lymphoma and mantle cell lymphoma using genetically modified autologous CD20-specific T cells. Blood 112, 2261-2271.

Valitutti, S., Muller, S., Cella, M., Padovan, E., and Lanzavecchia, A. (1995). Serial triggering of many T-cell receptors by a few peptide-MHC complexes. Nature 375, 148-151.

Van Gool, S.W., Vandenberghe, P., de Boer, M., and Ceuppens, J.L. (1996). CD80, CD86 and CD40 provide accessory signals in a multiple-step T-cell activation model. Immunological reviews 153, 47-83.

Vera, J., Savoldo, B., Vigouroux, S., Biagi, E., Pule, M., Rossig, C., Wu, J., Heslop, H.E., Rooney, C.M., Brenner, M.K., et al. (2006). T lymphocytes redirected against the kappa light chain of human immunoglobulin efficiently kill mature B lymphocytederived malignant cells. Blood 108, 3890-3897.

Vogler, I., Newrzela, S., Hartmann, S., Schneider, N., von Laer, D., Koehl, U., and Grez, M. (2010). An improved bicistronic CD20/tCD34 vector for efficient purification and in vivo depletion of gene-modified T cells for adoptive immunotherapy. Molecular therapy : the journal of the American Society of Gene Therapy 18, 1330-1338.

Wang, J., Jensen, M., Lin, Y., Sui, X., Chen, E., Lindgren, C.G., Till, B., Raubitschek, A., Forman, S.J., Qian, X., et al. (2007). Optimizing adoptive polyclonal $\mathrm{T}$ cell immunotherapy of lymphomas, using a chimeric $\mathrm{T}$ cell receptor possessing CD28 and CD137 costimulatory domains. Human gene therapy 18, 712-725.

Westwood, J.A., Murray, W.K., Trivett, M., Haynes, N.M., Solomon, B., Mileshkin, L., Ball, D., Michael, M., Burman, A., Mayura-Guru, P., et al. (2009). The Lewis-Y carbohydrate antigen is expressed by many human tumors and can serve as a target for genetically redirected $\mathrm{T}$ cells despite the presence of soluble antigen in serum. Journal of immunotherapy 32, 292-301.

Westwood, J.A., Smyth, M.J., Teng, M.W., Moeller, M., Trapani, J.A., Scott, A.M., Smyth, F.E., Cartwright, G.A., Power, B.E., Honemann, D., et al. (2005). Adoptive transfer of T cells modified with a humanized chimeric receptor gene inhibits growth of Lewis-Y-expressing tumors in mice. Proceedings of the National Academy of Sciences of the United States of America 102, 19051-19056.

Wilkie, S., Picco, G., Foster, J., Davies, D.M., Julien, S., Cooper, L., Arif, S., Mather, S.J., Taylor-Papadimitriou, J., Burchell, J.M., et al. (2008). Retargeting of human T cells to tumorassociated MUC1: the evolution of a chimeric antigen receptor. Journal of immunology 180, 4901-4909.

Yoon, S.H., Lee, J.M., Woo, S.J., Park, M.J., Park, J.S., Kim, H.S., Park, M.Y., Sohn, H.J., and Kim, T.G. (2009). Transfer of Her-2/neu specificity into cytokine-induced killer (CIK) cells with RNA encoding chimeric immune receptor (CIR). Journal of clinical immunology 29, 806-814. 
Zhang, H., Snyder, K.M., Suhoski, M.M., Maus, M.V., Kapoor, V., June, C.H., and Mackall, C.L. (2007a). 4-1BB is superior to CD28 costimulation for generating CD8+ cytotoxic lymphocytes for adoptive immunotherapy. Journal of immunology 179, 49104918.

Zhang, T., Barber, A., and Sentman, C.L. (2007b). Chimeric NKG2D modified T cells inhibit systemic T-cell lymphoma growth in a manner involving multiple cytokines and cytotoxic pathways. Cancer research 67, 11029-11036.

Zhao, Y., Moon, E., Carpenito, C., Paulos, C.M., Liu, X., Brennan, A.L., Chew, A., Carroll, R.G., Scholler, J., Levine, B.L., et al. (2010). Multiple injections of electroporated autologous T cells expressing a chimeric antigen receptor mediate regression of human disseminated tumor. Cancer research 70, 9053-9061.

Zhao, Y., Wang, Q.J., Yang, S., Kochenderfer, J.N., Zheng, Z., Zhong, X., Sadelain, M., Eshhar, Z., Rosenberg, S.A., and Morgan, R.A. (2009). A herceptin-based chimeric antigen receptor with modified signaling domains leads to enhanced survival of transduced T lymphocytes and antitumor activity. Journal of immunology 183, 5563-5574.

Zikherman, J., and Au-Yeung, B. (2015). The role of T cell receptor signaling thresholds in guiding $\mathrm{T}$ cell fate decisions. Current opinion in immunology 33, 43-48.

Zou, W. (2006). Regulatory T cells, tumour immunity and immunotherapy. Nature reviews Immunology 6, 295-307.
Cite this article as:

Vu, B., Le, D., \& Pham, P. (2016). Synergistic effect of chimeric antigen receptors and cytokineinduced killer cells: An innovative combination for cancer therapy. Biomedical Research and Therapy, 3(6), 653-665. 